\section{BREAKING BAD NEWS IN COMPLEX PALLIATIVE CARE SITUATIONS THROUGH ROLE-PLAY SIMULATION}

Carlos Laranjeira, Ana Isabel Querido. School of Health Sciences - Polytechnic of Leiria and cTecCare - Center for Innovative Care and Health Technology, Leiria, Portugal

10.1136/spcare-2021-PCC.55

Background One of the most important components in the repertoire of nursing communication skills is the ability to 'break bad news' to patients and families. This article presents a pilot role-play simulation conducted at a Portuguese undergraduate nursing program with senior-level students.

Methods The simulation was designed to aid nursing students to develop communication skills necessary to care for the critically ill patient nearing the EOL. This approach had two main learning outcomes: a) improve students' ability to break bad news and build their confidence in that ability, and b) assist students to engage in the process of self- and peer reflection. Thirty students were recruited from palliative care nursing course, they had no previous experience with this type of simulation. The simulation took place on three separate theoretical-practical classes with ten students each one. Prior to each role-play, three students were randomly role-played both the nurse, the patient and the relative roles. Students who were not assigned active roles observed the simulation and provided feedback during the debriefing period. Students were encouraged to reflect on issues related to the communication of bad news using the Gibbs' reflective cycle.

Results Themes of students' responses during the debriefing included an overall positive feeling about the experience and their performance $(n=25)$, nevertheless, students acknowledged they lacked confidence in their skills to communicate effectively $(n=12)$. They indicated that they felt more prepared to meet the patient's physical needs than emotional needs. All students also reported valuing working together as a team as it fostered meaningful sharing of ideas.

Conclusions As a result of this kind of learning, the student develops greater capacity for treating others with the respect and understanding required in palliative care nursing. This may inform his or her understanding and capacity to help the other person.

\section{8 'THE RIGHT INFORMATION TO THE RIGHT PEOPLE AT THE RIGHT TIME'- DESIGN AND DELIVERY OF A PALLIATIVE MEDICINE EDUCATION PROGRAMME DURING COVID-19}

Catherine Doherty, Sinead Hutcheson. Belfast Heath and Social Care Trust

\subsection{6/spcare-2021-PCC.56}

In the face of an overwhelming Coronavirus pandemic, Palliative Medicine guidelines, knowledge and skills are a crucial aspect of care for many seriously affected patients. Palliative care specialists can only treat a minority of dying patients therefore an educational intervention was needed to equip frontline staff. The education programme was delivered via a live virtual platform in weekly 1 hour education sessions. These were offered to community and hospital facing multidisciplinary staff within the Belfast Trust. Each session was followed by a live Q\&A with specialist staff. A total of 11 sessions delivered over 13 weeks reached approximately 528 health care professionals. Downar et $\mathrm{al}^{1}$ described four critical elements for palliative care provision in a pandemic - 'stuff', 'staff', 'space' and 'systems'. Program topics therefore included:

Recognising dying

Symptom Assessment and Management for patients with COVID 19

Advance Care Planning

After death care

Bereavement care

Self Care

The advantages of virtual education include accessibility, affordability and flexibility.

We conclude that it is possible to successfully provide a focused educational intervention on palliative care principles when resources are scarce. Disasters will continue to occur and technologies will play a part in helping us to cope with them.

\section{REFERENCE}

1. Downar J, Seccareccia D. Palliating a pandemic: 'All patients must be cared for'. J Pain Symptom Manage 2010;39:291"5.doi:10.1016/j.jpainsymman.2009.11.241 pmid:20152591

\section{VIRTUAL RESPONSE: AN EDUCATIONAL RESPONSE TO THE COVID-19 PANDEMIC}

Clare E Finnegan, Karen E Groves. Lancashire and South Cumbria NHS Foundation Trust, Queenscourt Hospice

\subsection{6/spcare-2021-PCC.57}

Background The Covid-19 pandemic resulted in a need for locality-wide pandemic-specific end-of-life education. Face-toface teaching was cancelled due to social distancing measures. A hospice education centre, already an ECHO (Extending Community Healthcare Outcomes) Hub, adapted their existing education programmes to meet local needs.

Methods Five ECHO Networks, established in March, ran over 10 weeks supporting local care homes, district nurses and GPs. Topics were agreed by participants, sessions led by a Palliative Medicine Consultant with multi-professional colleagues, and cases presented by the homes. Supporting resources were available via virtual learning environment (Moodle).

Additional bespoke Zoom sessions met specific training needs of nurses (verification of death (126), syringe driver competencies (92)) and other groups (GP trainees, local psychiatry teams). The Palliative Care Services visited all hospital wards daily delivering point-of-care training and local Covid19 End-of-Life Guidance. Training numbers were collated and feedback requested via survey monkey for ECHO network participants.

Results Over 1500 individual education contacts were recorded in 3 months (ECHO:625, Zoom:404, Point of Care: 471). Survey-monkey feedback from 28 ECHO participants rated the overall value of the ECHO network as 9.3/10. None reported technical problems with Zoom. They reported peer support and keeping up to date with rapidly changing information \& guidelines the most helpful elements. Learning was cascaded throughout teams. 